\title{
Application of observations of recent tectonic activity in the Świebodzice Depression (the Sudetes, SW Poland) in assessing seismic hazard in the Fore-Sudetic Monocline
}

\author{
Marek Kaczorowski ${ }^{1, *}$, Damian Kasza ${ }^{2}$, Ryszard Zdunek ${ }^{1}$, and Roman Wronowski ${ }^{1}$ \\ ${ }^{1}$ Polish Academy of Sciences, Space Research Centre, 18A Bartycka St., 00-716 Warszawa, Poland \\ ${ }^{2}$ Wrocław University of Science and Technology, Faculty of Geoengineering, Mining and Geology, 27 Wyb. Wyspiańskiego St., \\ 50-370 Wrocław, Poland
}

\begin{abstract}
Tiltmeter observations with application of horizontal pendulums have been carried out for 40 years in the Geodynamic Laboratory in Książ. Long-term observations have not indicated any correlation of these data with meteorological or seasonal phenomena. Following an epoch of fast azimuth changes, a gradual compensation process took place, excluding the effect of gravitational creep of the rock massif. An assumption was made that the observed large changes of the equilibrium azimuths of the horizontal pendulums that result from tectonic tilt of the foundation blocks. Multiannual tiltmeter observations allowed to determine the temporal characteristics and amplitude tectonic effects. Intervals of strong tectonic activity in the rock massif of the Świebodzice Depression last from several days to over ten weeks and are separated by several tens of hours of low activity. Amplitude of the rock massif deformation reaches values from over ten to several tens of amplitudes of the tidal signal, i.e. up to several hundreds of micrometres. Water-tube tiltmeters (WT) launched in 2003 have confirmed the characteristics of tectonic effects and their incidental occurrence. Beside the tilt effects, WT have enabled to confirm vertical movement of the foundation blocks. Geological investigations in the Swiebodzice Depression have indicated the presence of a numerous faults separating particular blocks in the rock massif. The presence of this fault system favours the dislocation of foundation blocks, which results in a quake-less relaxation of tectonic stresses and absence lack of seismic activity in the Świebodzice Depression. Foundation blocks separated by faults combined with the multiscale measurement system of WTs form a natural detector of regional tectonic activity, allowing to determine with micrometric resolution the representative function of tectonic activity in the rock massif of the Świebodzice Depression.
\end{abstract}

\section{Location and natural conditions of the Geodynamic Laboratory at Książ}

The Geodynamic Laboratory of the Space Research Centre of the Polish Academy of Sciences (GL) is located in the underground corridors under the Ksiąz Castle [1-3]. The laboratory is situated at the depth of ca $50 \mathrm{~m}$ below the courtyard of Książ Castle and ca $40 \mathrm{~m}$ above Pełcznica river valley. The foundation of the castle hill is built of (Książ Formation) of Devonian and Carboniferous Age conglomerates [4] composed mainly of metamorphic gneisses from the nearby Sowie Mts [57]. Conglomerates of the Świebodzice Basin have been noted to occur in the large depths of the Earth's crust [68].

Connection of the Książ Massif with deep layers of the Earth's crust [7] results in good translocation of a wide spectrum of geodynamic signals: seismic, tidal, Earth's oscillations and tectonic signals. This is confirmed by continuous observations of strong, nonattenuated geodynamic signals registered by the GL instruments: horizontal pendulums and water-tube tiltmeters, relative and absolute gravimeters, vacuum interferometric extensometer, TM-71 crack gauge [9, 10], and wide-range seismograph of the Institute of Geophysics, Polish Academy of Sciences.

The GL underground excavations are characterized by a stable temperature (annual oscillations of ca. $0.1^{\circ} \mathrm{C}$ ) and high relative humidity that varies seasonally at about $10 \%$ within $85 \%$ and $95 \%$. The natural conditions of the laboratory provide a stable setting for the observation of subtle geodynamic signals.

\section{Water-tube tiltmeters - the main source of geodynamic data}

The first reports on the tectonic activity in the Świebodzice Depression (ŚD) were devoted to the foundation dip registered since the 1970-ties by quartz horizontal pendulums [11]. The determined temporal and amplitude characteristics have been confirmed by new instruments - water-tube tiltmeters (WT).

* Corresponding author: marekk@cbk.waw.pl 
Due to the properties of horizontal pendulums such as instrumental drift, small dimensions of the measurement base and much lower sensibility than WT sensibility, pendulum tiltmeters are much less representative in the assessment of tectonic activity of the rock massif than the WT. At present, the source of information on the tectonic activity of the rock massif are two WT. For the determination of tectonic activity function two series of observations from WT were used (tectonic activity functions are defined in (see Chapter 3).

The main elements of WTs are two horizontal pipes that are perpendicular to one another, with a length of 65 and $92 \mathrm{~m}$ [12]. Interference gauges have been installed at the pipe ends, which register changes of water level related to the rock massif with regard to reference lenses with nanometric resolution.
The signal in form of a temporal chain of Newton rings is registered on hard discs and subsequently subjected to analysis that terminates with establishing a progressive function of the changes. The obtained measurement is relative to the rock massif, with which the reference lenses of the WT are firmly connected. A significant feature of WTs in measurements of the tectonic activity of a rock massif is their long measurement base. The WT measurement base (Fig. 1), i.e. the area from which the instruments collect information, is ca. $100 \mathrm{~m} \times 100 \mathrm{~m}$. Because this area is larger from the dimensions of single foundation blocks separated by faults, WT measurements supply information on the mutual vertical displacements and block tiltings, which guarantees high representativeness of the measurements in the assessment of momentous kinematic - tectonic activity of the rock massif.

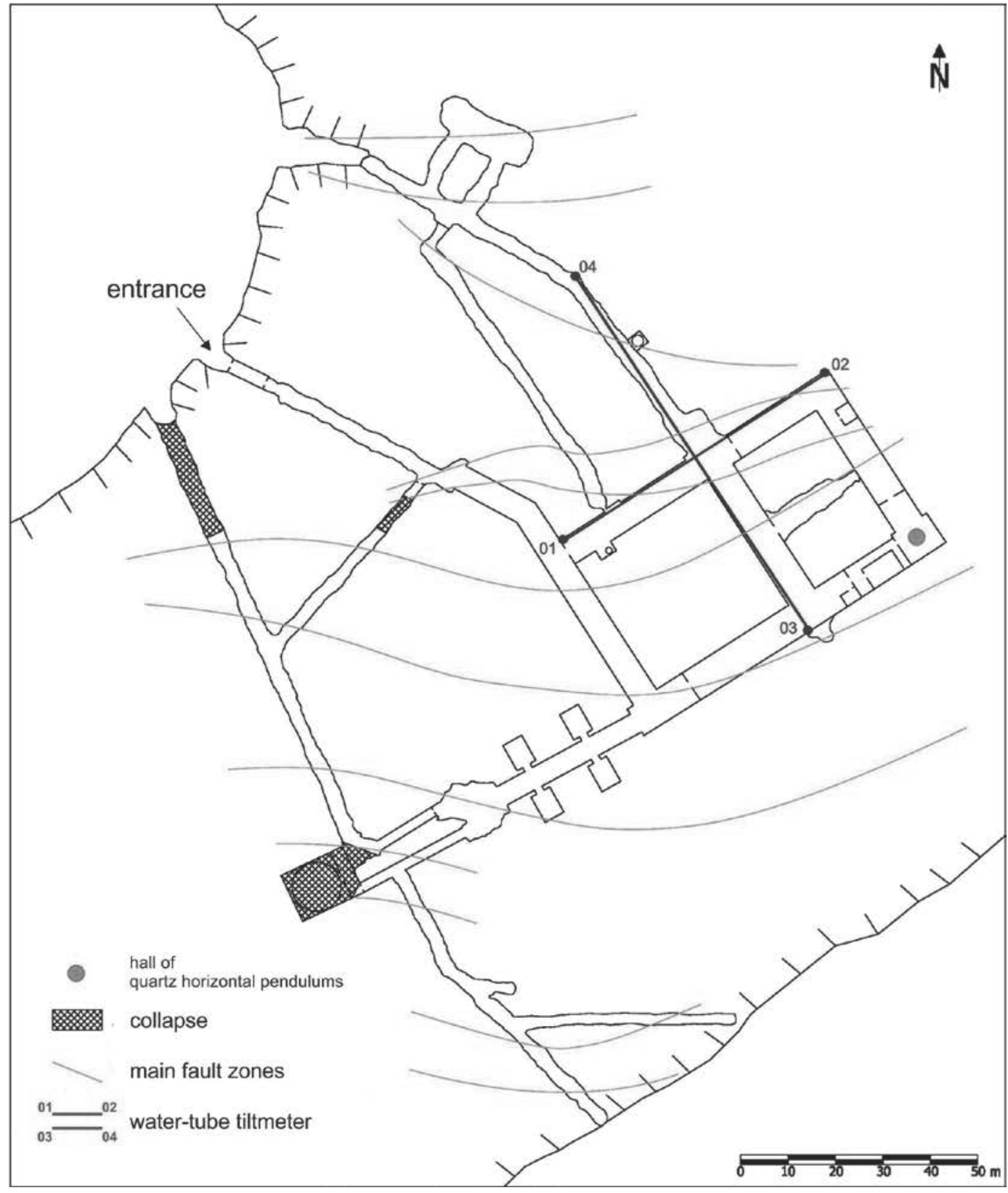

Fig. 1. Sketch-map of the underground excavations under the Książ Castle courtyard [13]. 
Changes of water level in the hydrodynamic systems of WTs are caused by two types of phenomena. The first type is related to external causes influencing Earth's gravity field, including loading effect, lunar and solar tidal phenomena as well as free oscillations of Earth's globe. The second type of phenomena registered by the WT are effects of tectonic origin [14-17]. The geodynamic activity of the rock massif is observed as tiltings effects and vertical displacements of the rock foundation [18]. Tectonic signals observed by WTs usually have much larger amplitude than the tidal signals. In extreme cases the tectonic signal exceeded the tidal signal several hundred-fold (in 2009 and 2010 on channel 03).

\section{Definition of the function of tectonic activity of the rock massif (TAF) and its determination}

The function of tectonic activity (TAF) was introduced to describe the magnitude and temporal changes of tectonic activity of the rock massif. This is an empirical function determined on the basis of measurements by WTs or other instruments with a sufficiently high sensibility for the deformations of the rock massif and a wide measuring base [19]. The tectonic activity registered by WTs is represented by two types of deformation: the tilt of the entire rock massif (argument a) and vertical displacements of the foundation blocks (function $r(l)$ ), where $a$ is the tilt of the massif and $r(l)$ is a function of the radial deformation of the foundation rock massif under the pipe of the tiltmeter [20]. The signals related to the vertical displacement of the rock massif are the integral of the vertical displacements of the foundation under WT pipes. WT measuring systems form a non-linear superposition of both types of deformation, whose mutual proportions vary in time. The tectonic signal registered by WTs is presented by the following formula:

$$
S(a, r(l))=L^{*} \cos (a)+\int_{l=0}^{l=L} r(l) d l
$$

where $L$ is the length of the tiltmeter pipe.

The TAF function is obtained from the $S(a, r(l))$ formula in several steps. In the first step, jumps and discontinuities caused by instrumental reasons or intense seismic phenomena are removed from the raw observation set. After removal of jumps and discontinuities, the effects of water evaporation and high-frequency signals are eliminated. Next, the measurement series are subject to tidal adjustment with help of ETERNA 3.4 software in order to remove the main part of the tidal signals and to determine the tectonic signal [21].

After additional adjusting by polynomial splines, TAF is obtained for each measurement channel of the WTs. Additional adjusting of the observation data is required due to the application of TAF for the determination of the function of deformation rate of the rock massif, i.e. VTAF - derivative of TAF.

\section{Temporal and amplitude relationships between tectonic activity of the Świebodzice Depression and the seismic activity of the Fore-Sudetic Monocline}

Elaboration of the observation series from WTs and determination of TAF derivatives allowed to discover the temporal and amplitude relationships between the rock massif activity of the Świebodzice Depression and the strong ( $>=4 \mathrm{Mag}$ ) seismic events in the Fore-Sudetic Monocline [22]. Comparative analysis of both types of phenomena lead to a conclusion that strong seismic shocks take place only at specific stages of tectonic activity of the ŚD rock massif. Stages of tectonic activity of the rock massif are described by the TAF functions and their derivatives (Fig. 2). Two basic intervals may be distinguished in the observed deformation process of the ŚD rock massif: interval of high rates of deformations and interval of low rates of deformations, during which the rates of deformations are close to zero, to later change their turn.

In the interval when the deformation stops and its rate changes sense, i.e. the rock massif transforms from the first to the second phase, the rock massif is in the state of extension - stretching for a short while. During the extension, lasting for a few to several tens of hours, significant changes take place in the rock massif, such as thickness increase of the dislocation zones, opening of fractures and fissures, gases outflow and decrease of the mean density of the rock massif. During the compression, the rock massif is subjected to high deformation rates lasting from several days to several tens of days, which are separated by extension phases lasting several tens of hours (Fig. 2).

The processes which take place in the rock massif during extension intervals, particularly the decrease of the mean density of the rock massif (dilution of the rock massif) favour the possibility of earthquake occurrence. The earthquakes are accompanied by rock massif destruction in form of fractures, crushing, strain, etc., causing volume increase and decrease of the mean values of rock massif density.

Based on these assumptions, a seismic shock occurs under the condition of existence of additional space within the rock massif, indispensable for the absorption of crushed material produced during the earthquake. This missing space is created when the rock massif is in the extension phase. Therefore, during the extension phase the rock massif becomes susceptible to destruction.

Comparative analysis of multiannual sequences of the TAF function with temporal distribution of strong seismic events confirms the above reasoning. All the strong seismic phenomena ( $>=4 \mathrm{Mag}, 26$ seismic events from the period of 2015-2016) took place at low rates of rock massif deformation, i.e. during extension phases. 


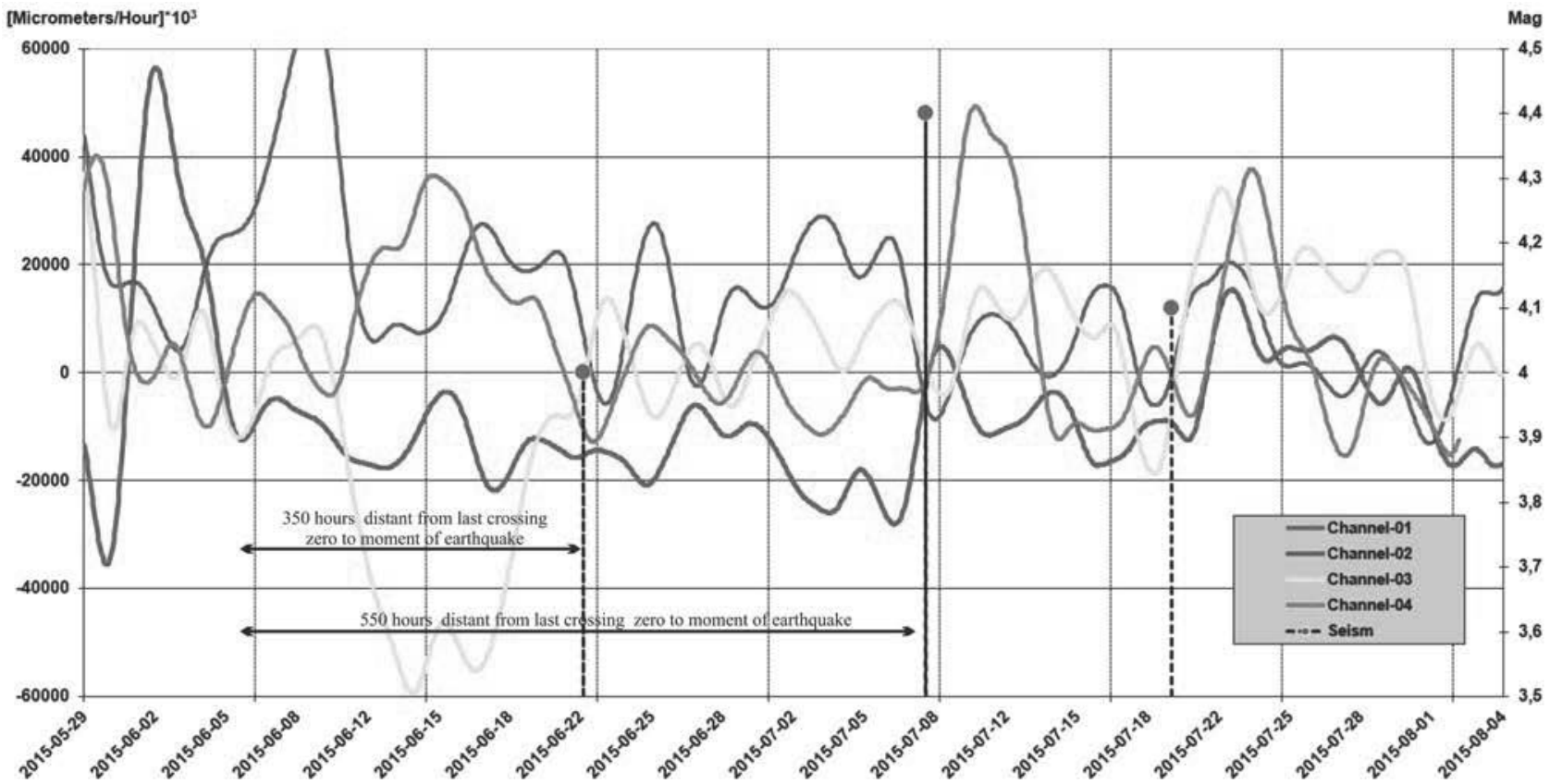

Fig. 2. 2015 - plots of derivatives of tectonic activity functions and the three strongest shocks: 4.0, 4.1 and 4.4 Mag.

\subsection{Temporal and amplitude rules of the process at which the rock massif is ready for a seismic shock}

The results of comparative analysis made for 26 seismic events (from 2015-2016; EMSC, 2017) allowed to conclude that the processes in the rock massif which precede seismic events follow a repeatable succession of rules. This observation allowed to include in the description of the process at which the rock massif becomes ready for a seismic shock, the temporal and amplitude rules consisting of a number of precedents.

Temporal precedents determine the time presented in hours since the last change of the sign of the TAF derivative on each WT measurement channels to the seismic shock. For every case of strong seismic event ( $>=4 \mathrm{Mag}$ ) from the years 2015-2016, the temporal characteristics correspond to the precedents described below (i.e. Fig. 3):

Precedent T-1: 4 passages through zero of the derivatives on all channels within ca. $100 \mathrm{~h}$ before the shock (very strong condition -very highly probable event during the next $100 \mathrm{~h}$ )

Precedent T-2: 3 passages through zero of the derivatives within ca. $100 \mathrm{~h}$ before the shock and preceding the passage up to $600 \mathrm{~h}$ before the shock (strong condition - seismic shock highly probable during the next $100 \mathrm{~h}$ )

Precedent T-3: 2 passages through zero within ca. $100 \mathrm{~h}$ before the shock and 2 preceding passes before $400 \mathrm{~h}$ before the shock (medium-strong condition shock probable during the next $100 \mathrm{~h}$ )

- $\quad$ Precedent T-4: 2 passages through zero within ca. $100 \mathrm{~h}$ before the shock and 2 symmetric channels postponed to $<600 \mathrm{~h}$.

Precedent T-5: 1 passage through zero within ca. $100 \mathrm{~h}$ before the shock and 3 focused passages up to 400 hours before the shock (medium-strong condition - shock probable during the next $100 \mathrm{~h}$ ).

The temporal intervals applied in the time precedents have been determined empirically.

Amplitude characteristics contain information of the values of the TAF derivatives at the moment of the seismic event observed on the 4 WT measurement channels. For all strong seismic events the amplitudes characteristics are described by the following amplitude precedents: four-fold concentration, three-fold concentration or two-fold concentration of the TAF derivative values in the interval of -20000 to 20000 $[\mu \mathrm{m} / \mathrm{h}]$ (i.e. Fig. 4; their magnitudes result from the 103 $[\mu \mathrm{m} / \mathrm{h}]$ multiplier used to operate on integer numbers):

- Precedent A-1: four-fold concentration close to zero (values of derivatives from -22000 to $22000[\mu \mathrm{m} / \mathrm{h}$ ] - very strong condition - high probability of seismic shock within $100 \mathrm{~h}$.

- Precedent A-2: three-fold concentration close to zero (values of derivatives from -22000 to $22000[\mu \mathrm{m} / \mathrm{h}]$ and 1 channel, in which value of derivative is $<60000$ $[\mu \mathrm{m} / \mathrm{h}]-$ strong condition - high probability of seismic shock within $100 \mathrm{~h}$.

- Precedent A-3: two-fold concentration close to zero and two-fold close concentration with values of derivatives from -25000 to $25000[\mu \mathrm{m} / \mathrm{h}]-$ strong condition - high probability of seismic shock.

- Precedent A-4: two-fold concentration close to zero with values of derivatives from -22000 to 22000 $[\mu \mathrm{m} / \mathrm{h}]$ and two-fold concentration for values $<60000$ $[\mu \mathrm{m} / \mathrm{h}]$.

Precedent A-5: two-fold concentration close to zero with values of derivatives from -20000 to 20000 $[\mu \mathrm{m} / \mathrm{h}]$ and two channels with mutually symmetrical values at a distance of $<80000[\mu \mathrm{m} / \mathrm{h}]$.

Precedent A-6: double two-fold concentrations with values of derivatives from -22000 to $22000[\mu \mathrm{m} / \mathrm{h}]$ 
symmetrical one to the other; high probability of seismic shock.

The numerical intervals applied in the definitions of amplitude precedents have been determined empirically.

Comparative analysis indicates that the essential condition for the occurrence of a seismic shock is the realization of temporal and amplitude precedents (Figs. $3,4)$. However, precedent fulfillment is not a condition sufficient for the occurrence of a seismic shock. In some cases, despite precedent fulfillment, a seismic shock did not occur in the extension phase.
We observed that before a seismic shock the TAF derivative change sign on all 4 WT measurement channels in an interval not exceeding $480 \mathrm{~h}$ before the seismic event. The inflection points of the TAF derivatives and an earlier change of the sign of the derivatives $(>780 \mathrm{~h})$, and the case when the derivative function is tangent to zero usually do not result in a shock. In the period 2015-2016 all 26 seismic shocks $(>=3.6 \mathrm{Mag})$ were preceded by the fulfillment of temporal and amplitude precedents by the TAF derivatives (see Fig. 3, 4, 5, 6 and Tables 1 and 2).

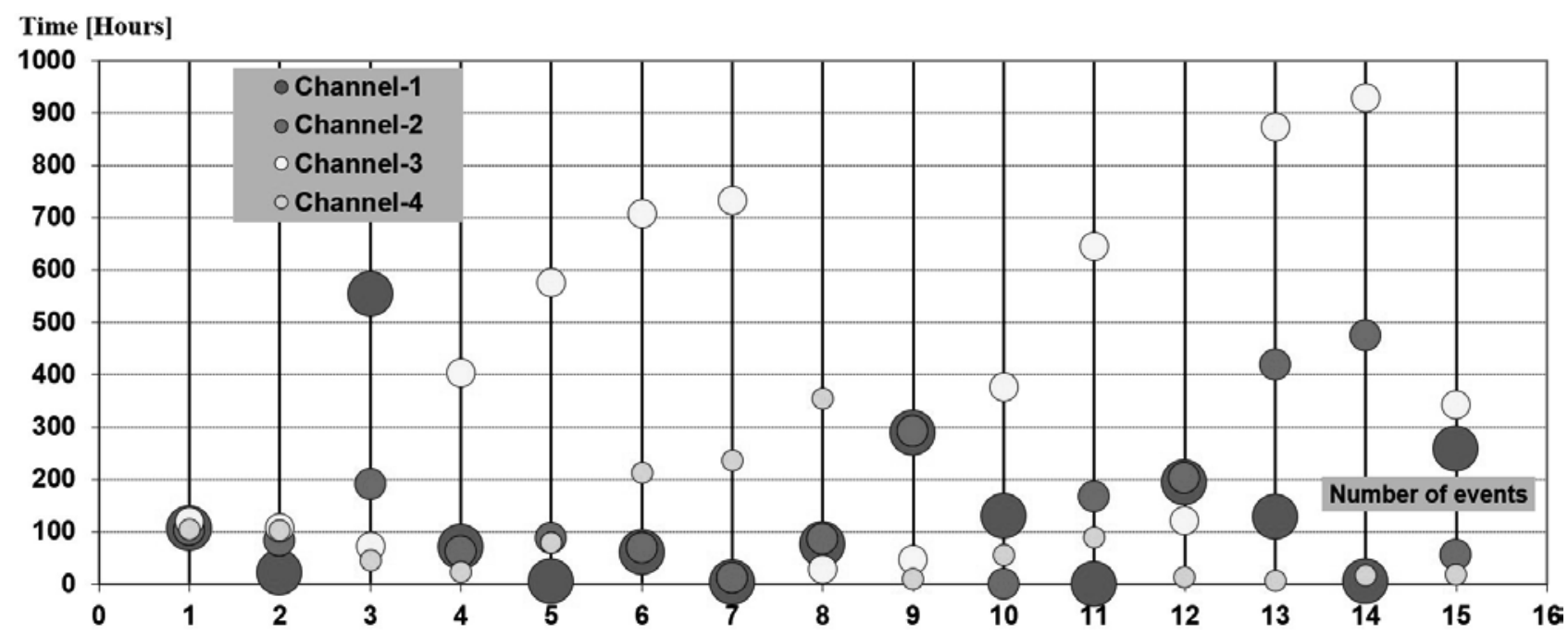

Fig. 3. 2016 - conditions for shock occurrence for 15 seismic events; temporal precedents T.

[Micrometers/Hour] ${ }^{*} 10^{3}$

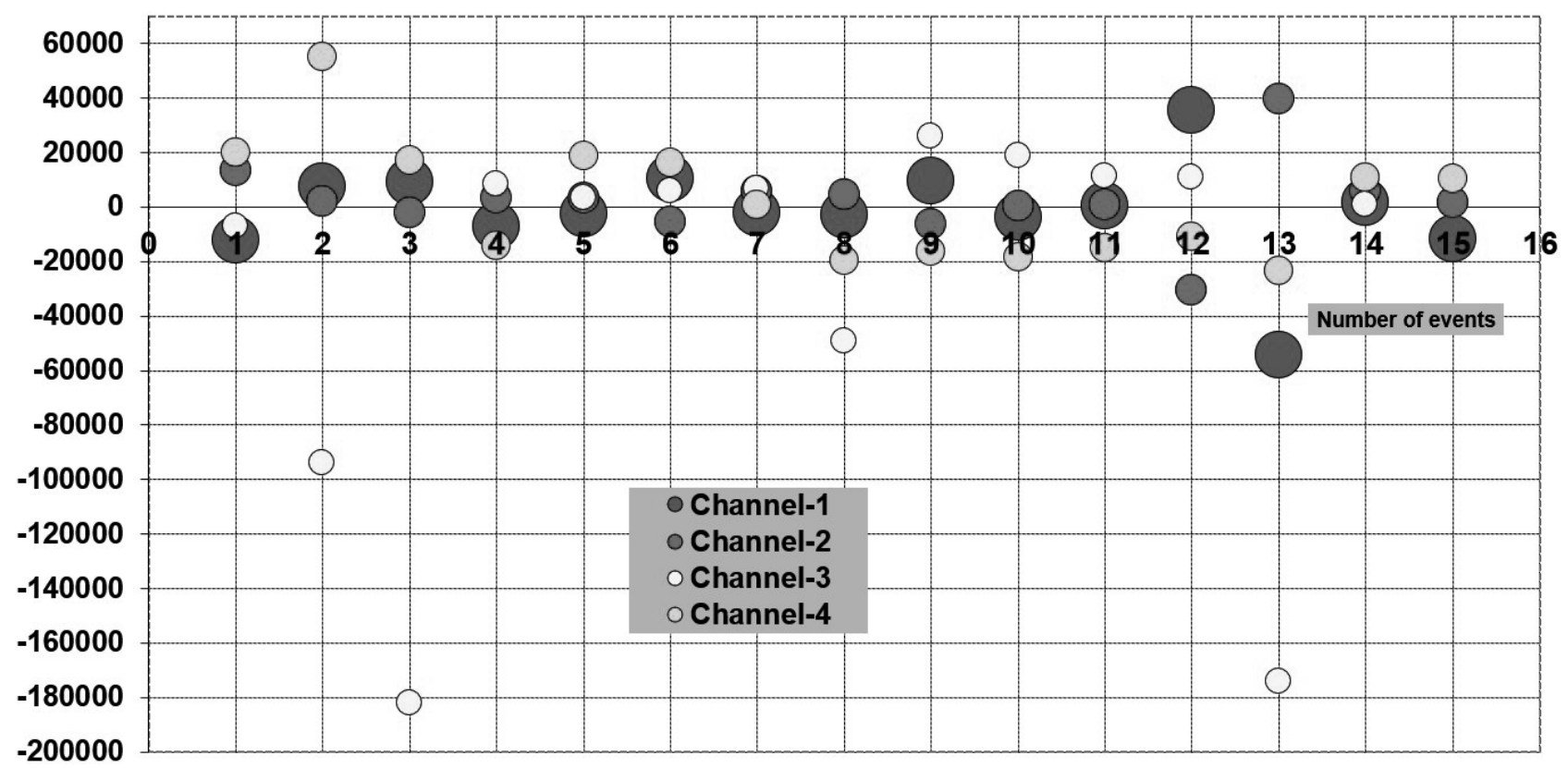

Fig. 4. 2016 - conditions for shock occurrence for 15 seismic events; amplitude precedents A. 


\section{Comparison of TAF derivatives with strong seismic events in the Fore- Sudetic Monocline in 2015-2016}

In 2015, eleven strong seismic shocks with magnitudes from 3.6 to $4.4 \mathrm{Mag}$ took place. All shocks occurred during the extension phase. No strong seismic shocks took place apart from the extension intervals (Tab. 1, Figs 2, 5, 6).

In 2016 there were 15 strong shocks with magnitudes from 3.6 to 4.4. All shocks occurred during the extension phases. No strong seismic shocks took place apart from the extension intervals (Tab. 2, Figs. 3, 4, 7).

Table 1. Temporal and amplitude precedents for 11 seismic events with magnitudes from 3.6 to 4.4 in 2015 [22].

\begin{tabular}{|c|c|c|c|c|c|c|}
\hline No. & Date & Mag & $\begin{array}{c}\text { Amplitude } \\
\text { precedents A }\end{array}$ & Description of amplitude precedents & $\begin{array}{c}\text { Temporal } \\
\text { precedents } \\
\text { T }\end{array}$ & $\begin{array}{c}\text { Description of temporal } \\
\text { precedents }\end{array}$ \\
\hline $\mathbf{1}$ & $2015-02-05$ & 3.9 & A-1B15 & $\begin{array}{c}\text { Four very close to zero, two-fold symmetry } \\
\text { medium + concentration }\end{array}$ & T-1A & $\begin{array}{c}\text { Four tight }- \text { close to } \\
\text { seismic moment }\end{array}$ \\
\hline $\mathbf{2}$ & $2015-02-12$ & 3.8 & A-1B15 & $\begin{array}{c}\text { Four very close to zero, ASYMMETRY + } \\
\text { three-fold concentration }\end{array}$ & T-1A & $\begin{array}{c}\text { Four tight }- \text { close to } \\
\text { seismic moment }\end{array}$ \\
\hline $\mathbf{3}$ & $2015-06-22$ & 4 & A-1B15 & $\begin{array}{c}\text { Four very close to zero, ASYMMETRY + } \\
\text { three-fold concentration }\end{array}$ & T-4A & $\begin{array}{c}\text { Single groupings } \\
\text { Type I }\end{array}$ \\
\hline $\mathbf{4}$ & $2015-07-08$ & 4.4 & A-1B15 & $\begin{array}{c}\text { Four very close to zero, ASYMMETRY + } \\
\text { three-fold concentration }\end{array}$ & T-3A & $\begin{array}{c}\text { Three close to zero tight }+ \\
\text { one distant }\end{array}$ \\
\hline $\mathbf{5}$ & $2015-07-19$ & 4.1 & A-1B15 & $\begin{array}{c}\text { Four very close to zero, ASYMMETRY + } \\
\text { three-fold concentration }\end{array}$ & T-3A & $\begin{array}{c}\text { Three close to zero tight + } \\
\text { one distant }\end{array}$ \\
\hline $\mathbf{6}$ & $2015-09-09$ & 4 & A-2B26 & $\begin{array}{c}\text { Three very close to zero, ASYMMETRY }+ \\
\text { three fold - strong concentration }- \\
\text { grouping nos. 212, 262 }\end{array}$ & T-4A & $\begin{array}{c}\text { Single groupings } \\
\text { Type I }\end{array}$ \\
\hline $\mathbf{7}$ & $2015-10-29$ & 4 & A-2A20 & $\begin{array}{c}\text { Three close to zero, very strong symmetry } \\
\text { (0.8 and 0.8) }\end{array}$ & T-4A & $\begin{array}{c}\text { Single groupings } \\
\text { Type I }\end{array}$ \\
\hline $\mathbf{8}$ & $2015-11-20$ & 3.7 & A-2A21 & $\begin{array}{c}\text { Three close to zero, ASYMMETRY }+ \\
\text { three-fold slight concentration - grouping } \\
\text { nos. 211, 261 }\end{array}$ & T-3A & $\begin{array}{c}\text { Three close to zero tight }+ \\
\text { one distant }\end{array}$ \\
\hline $\mathbf{9}$ & $2015-12-11$ & 3.8 & A-1B15 & $\begin{array}{c}\text { Four very close to zero, ASYMMETRY + } \\
\text { three-fold concentration }\end{array}$ & T-4B & $\begin{array}{c}\text { Two close to zero tight + } \\
\text { two tight }\end{array}$ \\
\hline $\mathbf{1 0}$ & $2015-12-28$ & 3.7 & A-1B15 & $\begin{array}{c}\text { Four very close to zero, ASYMMETRY + } \\
\text { three-fold concentration }\end{array}$ & T-3A & Two close to zero tight \\
\hline $\mathbf{1 1}$ & $2016-01-16$ & 3.7 & A-1B15 & $\begin{array}{c}\text { Four very close to zero, ASYMMETRY + } \\
\text { three-fold concentration }\end{array}$ & T-4A & $\begin{array}{c}\text { Three close to zero tight + } \\
\text { one distant }\end{array}$ \\
\hline
\end{tabular}

\section{Time [Hours]}

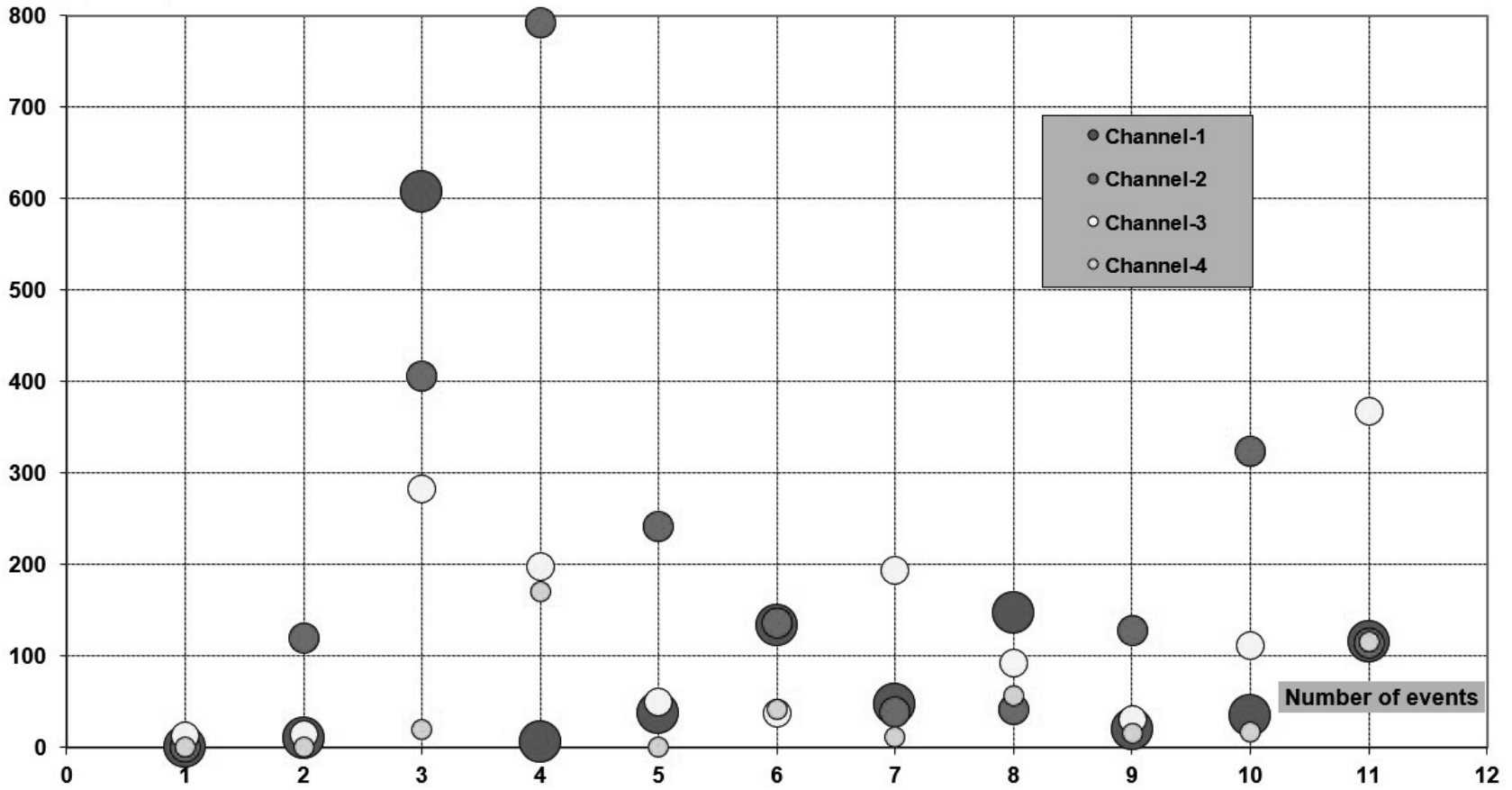

Fig. 5. The year 2015 - conditions for shock occurrence for 11 seismic events. Temporal precedents T. 


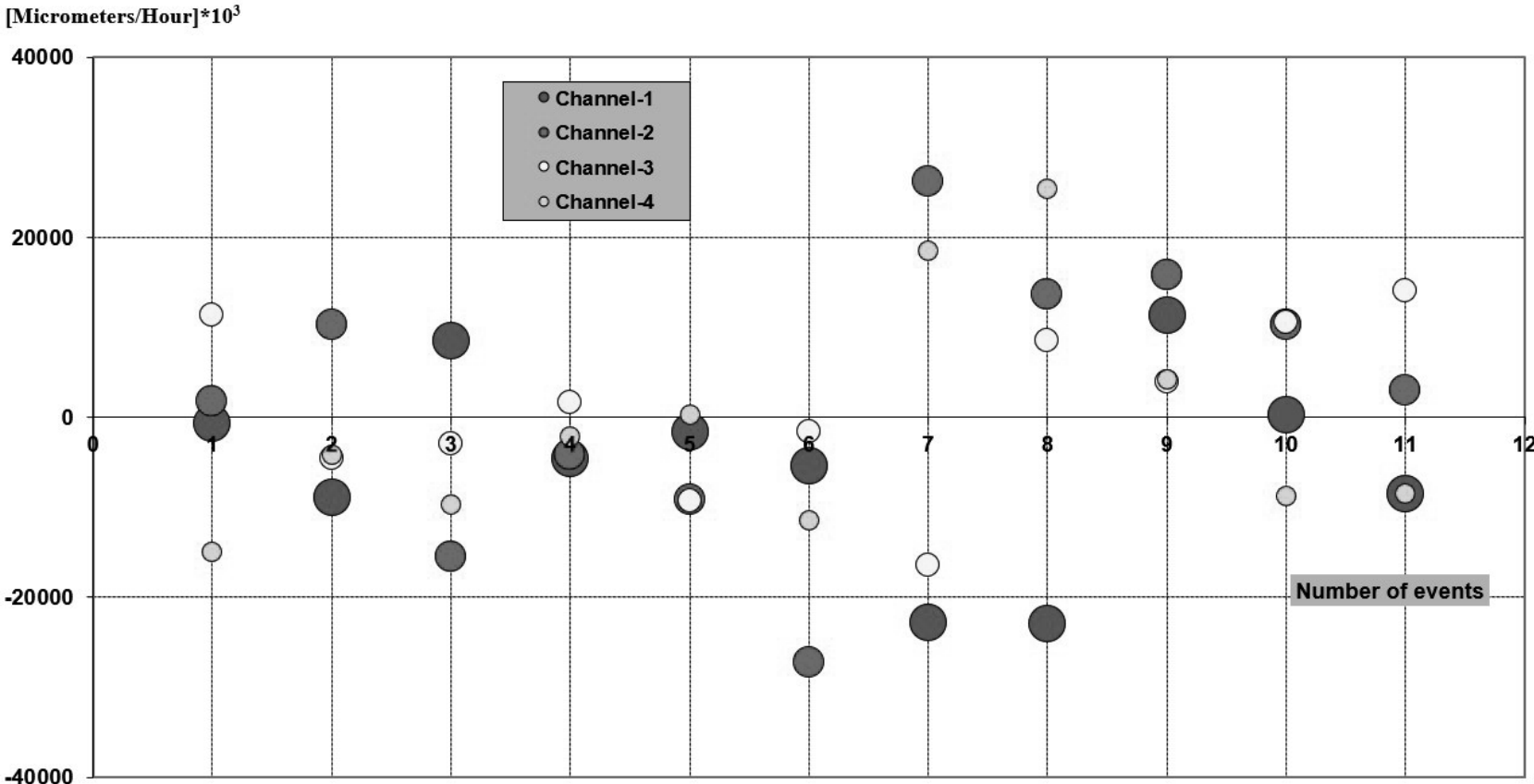

Fig. 6. The year 2015 - conditions for shock occurrence for 11 seismic events. Amplitude precedents A.

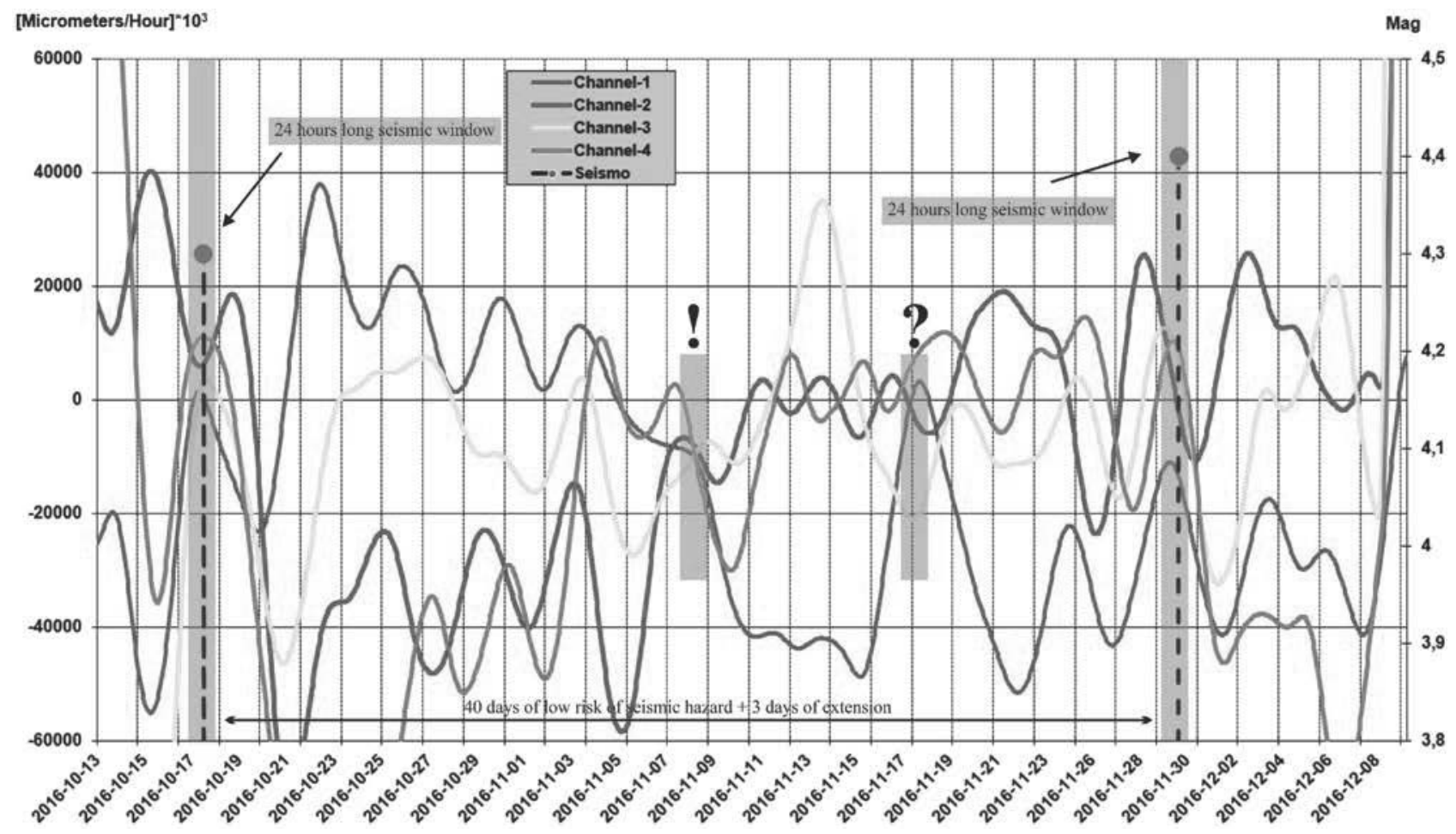

Fig. 7. 2016 - Plots of derivatives of tectonic activity functions and two strong shocks in: 2016-10-17 4.3 Mag and 2016-11-29 4.4 Mag. 
Table 2. Temporal and amplitude precedents for 15 seismic phenomena with magnitudes from 3.6 to 4.4 in 2016 [22].

\begin{tabular}{|c|c|c|c|c|c|c|}
\hline No. & Date & Mag & $\begin{array}{c}\text { Amplitude } \\
\text { precedents A }\end{array}$ & $\begin{array}{l}\text { Description of amplitude } \\
\text { precedents }\end{array}$ & $\begin{array}{l}\text { Temporal } \\
\text { precedents } \\
\mathbf{T}\end{array}$ & $\begin{array}{l}\text { Description of temporal } \\
\text { precedents }\end{array}$ \\
\hline 1 & $2016-02-25$ & 4.1 & A-1B15 & $\begin{array}{l}\text { Four very close to zero, } \\
\text { ASYMMETRY + two } \\
\text { concentrations }\end{array}$ & $\mathrm{T}-1 \mathrm{~A}$ & $\begin{array}{c}\text { Four tight }- \text { close to seismic } \\
\text { moment }\end{array}$ \\
\hline 2 & 2016-03-08 & 3.6 & A-3B36 & $\begin{array}{c}\text { Two very close to zero, strong } \\
\text { single symmetry - groupings } \\
\text { nos. } 308,358 \\
\end{array}$ & $\mathrm{~T}-1 \mathrm{~A}$ & $\begin{array}{l}\text { Four tight - close to seismic } \\
\text { moment }\end{array}$ \\
\hline 3 & 2016-04-08 & 3.7 & A-2B25 & $\begin{array}{l}\text { Three very close to zero, very } \\
\text { poor symmetry }\end{array}$ & $\mathrm{T}-4 \mathrm{~A}$ & Single grouping Type I \\
\hline 4 & 2016-04-28 & 3.6 & A-1B15 & $\begin{array}{c}\text { Four very close to zero, medium } \\
\text { symmetry }+ \text { concentration }\end{array}$ & $\mathrm{T}-3 \mathrm{~A}$ & $\begin{array}{c}\text { Three close to zero tight }+ \\
\text { one distant }\end{array}$ \\
\hline 5 & 2016-05-05 & 3.7 & A-1B15 & $\begin{array}{l}\text { Four very close to zero, } \\
\text { ASYMMETRY + three-fold } \\
\text { concentration }\end{array}$ & $\mathrm{T}-3 \mathrm{~A}$ & $\begin{array}{l}\text { Three close to zero tight }+ \\
\text { one distant }\end{array}$ \\
\hline 6 & 2016-05-11 & 3.9 & A-1B15 & $\begin{array}{c}\text { Four very close to zero, } \\
\text { ASYMMETRY + three-fold } \\
\text { concentration } \\
\end{array}$ & $\mathrm{T}-4 \mathrm{~A}$ & Single grouping Type I \\
\hline 7 & 2016-05-12 & 3.8 & A-1B15 & $\begin{array}{l}\text { Four very close to zero, } \\
\text { ASYMMETRY + three-fold } \\
\text { concentration }\end{array}$ & $\mathrm{T}-4 \mathrm{~A}$ & Single grouping Type I \\
\hline 8 & 2016-06-02 & 4.1 & A-2B26 & $\begin{array}{c}\text { Three very close to zero, } \\
\text { ASYMMETRY + poor three- } \\
\text { fold concentration - groupings } \\
\text { nos. } 211,261\end{array}$ & $\mathrm{~T}-3 \mathrm{~A}$ & $\begin{array}{l}\text { Three close to zero tight }+ \\
\text { one distant }\end{array}$ \\
\hline 9 & 2016-07-30 & 4.4 & A-2B25 & $\begin{array}{l}\text { Three very close to zero, poor } \\
\text { symmetry }(0.5 \text { and } 0.5)\end{array}$ & $\mathrm{T}-4 \mathrm{~B}$ & $\begin{array}{c}\text { Two close to zero tight }+ \text { two } \\
\text { tight }\end{array}$ \\
\hline 10 & $2016-08-13$ & 4.3 & A-1B15 & $\begin{array}{l}\text { Four very close to zero, very } \\
\text { poor symmetry }\end{array}$ & $\mathrm{T}-3 \mathrm{~A}$ & Two close to zero tight \\
\hline 11 & 2016-08-24 & 3.8 & A-1B16 & $\begin{array}{c}\text { Four very close to zero, } \\
\text { ASYMMETRY + single-fold } \\
\text { concentration }\end{array}$ & $\mathrm{T}-4 \mathrm{~A}$ & $\begin{array}{l}\text { Three close to zero tight }+ \\
\text { one distant }\end{array}$ \\
\hline 12 & 2016-09-14 & 4.1 & A-3B35 & $\begin{array}{l}\text { Two very close to zero, very } \\
\text { strong two-fold symmetry- } \\
\text { groupings nos. } 304,354\end{array}$ & $\mathrm{~T}-4 \mathrm{~B}$ & Single grouping Type I \\
\hline 13 & $2016-10-15$ & 3.7 & A-4A30 & $\begin{array}{l}\text { One close to zero-DETAILS } \\
\text { missing-groupings nos. } 30,35\end{array}$ & $\mathrm{~T}-4 \mathrm{~A}$ & $\begin{array}{c}\text { Two close to zero tight }+ \text { two } \\
\text { distant }\end{array}$ \\
\hline 14 & 2016-10-17 & 4.3 & A-1B15 & $\begin{array}{l}\text { Four very close to zero, } \\
\text { ASYMMETRY + three-fold } \\
\text { concentration }\end{array}$ & $\mathrm{T}-4 \mathrm{~A}$ & Two close to zero tight \\
\hline 15 & 2016-11-29 & 4.4 & A-1B15 & $\begin{array}{l}\text { Four very close to zero, } \\
\text { ASYMMETRY + three-fold } \\
\text { concentration }\end{array}$ & $\mathrm{T}-4 \mathrm{~B}$ & $\begin{array}{c}\text { Two close to zero tight }+ \text { two } \\
\text { tight }\end{array}$ \\
\hline
\end{tabular}

\section{Summary and conclusions}

Comparative analysis of the tectonic activity of the Świebodzice Depression rock massif with the seismic events in the Fore-Sudetic Monocline indicated that all 26 strong seismic shocks $(>=3.6 \mathrm{Mag})$ occurred in the years 2015-2016 during the extension phases, i.e. at the low rates of the rock massif deformations. In the compression phases, i.e. at high rates of rock massif deformation, no strong seismic shock $(>=3.6 \mathrm{Mag})$ happened. Detection of the high temporal concordance of the massif extension intervals in the Swiebodzice Depression with the 26 strong seismic events $(>=3.6$ Mag) in 2015-2016 provides significant arguments to support the concept of a large-scale, homogeneous field of tectonic forces, covering two geological units, i.e. the Świebodzice Depression and the Fore-Sudetic Monocline at the same time.
Comparative investigations of the tectonic activity of the Świebodzice Depression with the seismic events in the Fore-Sudetic Monocline lead to the conclusion that the processes in the rock massif, which precede seismic event, follow a repeatable succession of rules.

Gathered observations allowed to introduce the description of the process of adaptation of the rock massif to fulfill the conditions for seismic shock occurrence. This description comprises temporal and amplitude rules, composed with a number of precedents.

We noticed the essential condition for the occurrence of an earthquake in the Monocline which is the rule of passage through zero of four derivatives of the TAF at ca. $100 \mathrm{~h}$ before the shock and the rule of concentration around zero of values of most derivatives on the most channels within the range 22000 and -22000 $(\mu \mathrm{m} / \mathrm{h} * 1000$; Tables 1 and 2$)$. 
Results of comparative analysis indicate that after fulfil temporal and magnitudes rules seismic hazard in the Fore-Sudetic Monocline increase. The presented method allowed for determining the intervals of low rates of the rock massif deformation, i.e. the intervals of extension within the years 2015-2016, during which 26 seismic events $(>=3.6 \mathrm{Mag})$ took place. A stronger shock results in better application of the determined rules.

A regularity was noted that the correlation of lowenergy shocks with intervals of low rates of deformations (extension intervals) is worse than correlation of high-energy shocks. This observation suggests that probable the low-energy shocks are generated by mining activity in contrast to the highenergy shocks of tectonic nature which are well correlated with tectonic activity of ŚD.

For unknown reasons, in a few extension intervals strong seismic shocks did not take place despite the fulfilment of temporal and magnitude precedents conditioning the occurrence of earthquakes. The acquired knowledge allows for recognising almost all strong seismic events $(>=3.6 \mathrm{Mag})$, which enables us to forecasting of the seismic hazard in the Fore-Sudetic Monocline. It is worth mentioning that the presented idea is not applicable for unambiguous prediction of the earthquakes.

This work was financed by the Polish Statutory Research Grant no. 0402/0137/16 and MNiSW no. 6158/E-73/SPUB/2016/3-1.

\section{References}

1. B. Rdułtowski, The Hunt for Wunderwaffe - Hitler's Secret Weapon from the Owl Mountains (Technol, 2012)

2. "History of AL Riese", Gross-Rosen Museum in Rogoźnica. http://en.gross-rosen.eu/historia-klgross-rosen/historia-al-riese/, retrieved 7 October 2017

3. P. Zagożdżon, K. Zagożdżon, Hereditas Minariorum 3, 267-279 (2016)

4. H. Teisseyre and O. Gawroński, Detailed Geological Map of the Sudetes, 1:25,000, Świebodzice sheet, Państwowy Instytut Geologiczny, Warszawa (1965)

5. W. Nemec, S.J. Porębski, R.J. Steel, Sedimentology, 27, 519-538 (1980)

6. S.J. Porębski, Geologia Sudetica, 16, 1, 99-190 (1981)

7. S.J. Porębski, N. Jb. Geol. Paläont. Abh., 179, 259274 (1990)

8. A. Żelaźniewicz, P. Aleksandrowski, Przegląd Geologiczny, 56, 10, 904-911(2008; in Polish with English abstract)

9. D. Kasza, M. Kaczorowski, R. Zdunek, R. Wronowski, 2014, Acta Geodynamica et Geomaterialia, 11, No. 3 (175), 225-234 (2014)

10. R. Zdunek, M. Kaczorowski, D. Kasza, R. Wronowski, Acta Geodynamica et Geomaterialia, 11, No. 4 (176), 305-315 (2014)
11. T. Chojnicki, P.A. Blum, Artificial Satellites, vol. 31, no. 3, 123-129 (1996)

12. M. Kaczorowski, Earthquake Source Asymmetry, Structural Media and Rotation Effects (SpringerVerlag, 493-520, 2006)

13. D. Kasza, PhD dissertation, Wrocław University of Science and Technology, unpublished (2016; in Polish)

14. M. Kaczorowski, Acta Geodynamica et Geomaterialia, 4, 4, 109-119 (2007)

15. M. Kaczorowski, Reports on Geodesy, 85, 2, 79-86 (2008)

16. M. Kaczorowski, Acta Geodynamica et Geomaterialia, 6, 3, 369-381 (2009)

17. M. Kaczorowski, Bulletin d'Information des Marées Terrestres (BIM), 144, 11605-11613 (2009)

18. M. Kaczorowski, J. Wojewoda, Acta Geodynamica et Geomaterialia, 8, No. 3(163), 1-13 (2011)

19. H.E. Ruotsalainen, Lithosphere 2008 symposium Oulu, Finland, extended abstracts, Report S-53, Institute of Seismology, University of Helsinki (2008)

20. D.R. Bower, Phil. Trans. R. Soc. Lond. A, 274, 223226 (1973)

21. H.-G. Wenzel, Obs. Royal de Belgique, Bull. Inform. Marées Terr., 124, 9425-9439 (1996)

22. European Mediterranean Seismological Centre, https://www.emsc-csem.org, retrieved 7 October 2017 